\title{
Educação popular, saúde e segurança alimentar em áreas do Movimento dos Trabalhadores Rurais Sem Terra
}

\section{Popular education, health and food safety in agrarian reform areas of the Landless Rural Workers 'Movement}

\section{Educación popular, salud y seguridad alimentaria en las áreas del Movimiento de los Trabajadores Rurales Sin Tierra}

Bianca RÜCKERT ${ }^{1}$

Marília Carla de Mello GAIA ${ }^{2}$

\section{RESUMO}

Este artigo analisa o desenvolvimento de uma ação educativa em segurança alimentar e nutricional envolvendo o Movimento dos Trabalhadores Rurais Sem Terra, na região Metropolitana de Belo Horizonte, Minas Gerais. A partir do registro da experiência, enfatizou-se a metodologia da ação, os saberes mobilizados e as mudanças nas práticas de saúde, segurança alimentar e produção agropecuária dos sujeitos envolvidos. As reflexões apontam para alguns elementos da metodologia que contribuíram para o desenvolvimento da referida ação educativa, para a construção de uma concepção ampliada sobre o processo saúde-doença a partir da inter-relação entre saúde, produção, alimentação e práticas populares de cuidado, além dos desafios e potencialidades ao fortalecimento da segurança alimentar e nutricional nas áreas de Reforma Agrária que integraram a experiência.

Palavras-chave: saúde da população rural; segurança alimentar e nutricional; Movimento dos Trabalhadores Rurais Sem Terra; agroecologia; diálogo de saberes.

\section{ABSTRACT}

This article analyses the development of an educational action on food and nutritional safety involving the Landless Rural Workers' Movement in the Metropolitan region of Belo Horizonte, Minas Gerais. Based on the experience report, it emphasizes the action methodology, the mobilized knowledge and the changes in health practices, food safety and agricultural production of the subjects involved. The reflections point to some elements of the methodology that contributed 1 Farmacêutica, mestre em Educação (UFMG), especialista em Movimentos Sociais (UFMG) e integrante do Movimento dos Trabalhadores Rurais Sem Terra de Minas Gerais. Contato: biaruckert@yahoo.com.br

2 Bióloga, doutoranda em Educação (UFMG), mestre em Ciências / ênfase Saúde Coletiva (CPqRR-Fiocruz-MG) e especialista em Agroecologia e Desenvolvimento Sustentável (IFSudesteMG), integrante do Movimento dos Trabalhadores Rurais Sem Terra de Minas Gerais. Contato: marilia.gaia@gmail.com 
to the development of this educational activity; to the building of an expanded conception of the health-sickness process from the inter-relationship among health, production, food and popular care practices; besides the challenges and potentialities for the strengthening of food and nutritional security in the agrarian reform areas that integrated the experience.

Keywords: Rural Population Health; food and nutritional security; Landless Rural Workers' Movement; Agroecology; dialogue of knowledge.

\section{RESUMEN}

En este artículo se analiza el desarrollo de una acción educativa en la seguridad alimentaria y nutricional que involucra el Movimiento de los Trabajadores Rurales Sin Tierra en la Región Metropolitana de Belo Horizonte, Minas Gerais. A partir del registro de la experiencia, se enfatizó en la metodología de acción, el conocimiento movilizado y los cambios en las prácticas de salud, seguridad alimentaria y la producción de los sujetos involucrados. Las reflexiones apuntan para algunos elementos de la metodología que contribuyeron a su desarrollo; para la construcción de una concepción ampliada acerca del proceso salud-enfermedad a partir de la interrelación entre salud, producción, alimentación y prácticas populares de cuidados, además de los desafíos y potencialidades del fortalecimiento de la seguridad alimentaria y nutricional en las áreas de reforma agraria que integraron la experiencia.

Palabras-clave: salud de las poblaciones del campo; seguridad alimentaria y nutricional; Movimiento de los Trabajadores Rurales Sin Tierra; agroecología; diálogo de saberes.

\section{INTRODUÇÃO}

No âmbito de assentamentos e acampamentos da Reforma Agrária, diversos podem ser os temas geradores para desencadear processos educativos (formais e informais) no próprio território (no caso, o campo), que façam a devida (e necessária) transição do "mundo das ideias" para o "plano da realidade concreta", efetivando então a construção de metodologias e práticas na lógica da Educação popular ${ }^{2,3}$ e da Ecologia de saberes ${ }^{4,5}$.

As abordagens educativas no universo do campo, marcadas pela concepção da Educação do Campo, buscam colocar em relação as diversas formas de conhecimento marcadamente presentes entre os sujeitos do campo. Os conhecimentos escolares, os conhecimentos científicos, os conhecimentos populares ou empíricos, o senso comum, entre outros, incompreensíveis para o conhecimento positivista moderno, fazem parte da construção de saberes e das experiências do/no campo.

Santos nos chama a atenção para a linha abissal que separa o conhecimento moderno e os conhecimentos populares, camponeses, indígenas, uma vez que, sendo abissal a separação entre estes últimos e o primeiro, estes são considerados inexistentes (no sentido de não relevantes ou não // Tempus, actas de saúde colet, Brasília, 8(2), 157-171, jun, 2014.

ISSN 1982-8829 
compreensíveis) e não devem figurar como conhecimentos válidos.

Diversas experiências da Educação do Campo buscam minimizar as assimetrias entre tantos e distintos saberes, tentando reconhecer seus limites e possibilidades, de forma a qualificar a práxis dos sujeitos, dialogando assim com os modos de produção e de reprodução da vida no campo. Fica aqui expressa então a ideia de Ecologia de Saberes de Boaventura de Sousa Santos e também da Educação Popular:

[a ecologia de saberes] confronta a monocultura da ciência moderna [...] na medida em que se funda no reconhecimento da pluralidade de conhecimentos heterogêneos (sendo um deles a ciência moderna) e em interações sustentáveis e dinâmicas entre eles sem comprometer sua autonomia. A ecologia de saberes se baseia na ideia de que o conhecimento é interconhecimento. [...] Na ecologia de saberes cruzam-se conhecimentos e também ignorâncias. Não existe uma unidade de conhecimento, assim como não existe uma unidade de ignorância.

[...] a expressão educação popular designa a educação feita com o povo, com os oprimidos ou com as classes populares, a partir de uma determinada concepção de educação: a educação libertadora.

Na perspectiva da Educação Popular e da Ecologia de Saberes, a discussão da Soberania e Segurança Alimentar e Nutricional (SSAN) aponta-se como um tema gerador possível para diálogo e construção de saberes para/com os sujeitos do campo. Além do que, a construção da SSAN trás à tona a necessidade de discussão e desenvolvimento de estratégias de enfrentamento do modelo de desenvolvimento vigente, a partir de um novo olhar sobre a educação, a saúde, a produção agropecuária e, especificamente, sobre a alimentação.

No contexto globalizado, os hábitos alimentares têm se modificado ao longo dos anos, sendo substituídos os alimentos nativos e frescos pelos alimentos industrializados. Temos, então, de um lado a "indústria alimentar induzindo à má alimentação" e, do outro, a indústria química e farmacêutica aproveitando-se "das carências nutricionais das pessoas para vender produtos, como vitaminas". Sem contar a indústria agropecuária que incentiva a produção uniforme, híbrida e sintética, altamente dependente dos insumos químicos. Vale destacar que, muitas vezes, a mesma empresa transnacional que controla a produção e comercialização de medicamentos controla também o mercado das sementes e dos agrotóxicos, criando, assim, um círculo vicioso: mais veneno, menos saúde, mais doenças, mais remédios, mais lucros.

Paralelamente a este fenômeno, presenciamos, em escala mundial, ao fortalecimento de um modelo agrícola que propõe a concentração de terra, a perda da biodiversidade e o domínio do sistema agroalimentar por parte de corporações transnacionais. 
Em um projeto de extensão universitária de Educação Popular em Saúde desenvolvido em oito assentamentos e acampamentos organizados pelo Movimento dos Trabalhadores Rurais Sem Terra em Minas Gerais (MST-MG), ocorrido por meio de uma parceria entre a Faculdade de Educação da Universidade Federal de Minas Gerais (UFMG) e o MST-MG ${ }^{3}$, a temática Segurança Alimentar e Nutricional apresentou-se como uma das estratégias educativas na busca por melhoria nas condições de vida e saúde nessas áreas. Essa experiência, desenvolvida durante o período de maio de 2008 a janeiro de 2009, teve como objetivos: contribuir para a valorização e a socialização de saberes e práticas populares de saúde e o fortalecimento de experiências de saúde; e contribuir para a participação dessas/es trabalhadoras/es nas políticas públicas de saúde. O eixo central da experiência consistiu na organização das/os trabalhadoras/es em torno das questões de saúde dos acampamentos/assentamentos envolvidos. Nessa experiência buscou-se desenvolver a reflexão sobre os determinantes sociais de saúde das comunidades e a elevação da consciência do direito à saúde, expressa na busca por acesso ao cuidado e a melhores condições de vida.

Neste artigo apresentamos um relato de parte desta experiência de Educação Popular, considerando-se o recorte da Segurança Alimentar e Nutricional (SAN). Para tal, consideramos três áreas de Reforma Agrária localizadas na região metropolitana de Belo Horizonte (Minas Gerais). Através da vivência como educadoras populares atuantes do MST e pesquisadoras, as autoras deste artigo buscaram registrar e refletir sobre o processo desenvolvido e sobre algumas mudanças observadas nas práticas de saúde e segurança alimentar e nutricional das/os trabalhadoras/es rurais envolvidas/os no processo.

Para isso, foi utilizado o instrumento do Caderno de Campo, no qual foram registradas as atividades desenvolvidas, as discussões realizadas pelo grupo, as reflexões e questionamentos sobre a prática, além do registro dos avanços e desafios percebidos, buscando-se um diálogo com o referencial teórico norteador da experiência em desenvolvimento.

Ressalta-se que a abordagem metodológica da experiência aqui relatada é a Educação Popular, entretanto, a discussão da Ecologia de Saberes soma-se posteriormente ao processo de análise e reflexão da experiência.

Faz-se necessário destacar que este relato insere-se na perspectiva da Pesquisa Militante, a qual reconhece o papel central da canonização do saber científico na "sistemática global do capitalismo e na perpetuação de suas enormes desigualdades" e, por sua vez, busca a construção de "formas não hegemônicas de produção e reprodução do conhecimento", orientando-se por uma ação transformadora7.

Assim, a Pesquisa Militante "se efetiva por meio de um processo dialético que inclui a interação entre a teoria e a prática para a produção do saber", associando à "práxis social uma dimensão reflexiva e crítica, onde a pesquisa se confunde com as experiências, as práticas e as dinâmicas 3 Projeto "Atenção à Saúde do Campo: Contribuiçães da Educação Popular", desenvolvido com o apoio da Secretaria de Gestão Estratégica e Participativa do Ministério da Saúde (SEGEP), com recursos do Fundo Nacional de Saúde. 
sociais".

\section{Segurança Alimentar e Nutricional, Agroecologia e Saúde no Movimento dos Trabalhadores Rurais Sem Terra}

A Segurança Alimentar e Nutricional (SAN) é a realização do direito de todos/as ao acesso regular e permanente a alimentos de qualidade, "em quantidade suficiente, sem comprometer o acesso a outras necessidades essenciais, tendo como base práticas alimentares promotoras de saúde, que respeitem a diversidade cultural e que sejam social, econômica e ambientalmente sustentáveis". Esse é um conceito em construção, conforme Gadelha e Weitzman, no qual "não se pode reduzir o movimento em prol da segurança alimentar e nutricional à luta para matar a fome da população brasileira, pois existem muitas dimensões a serem exploradas".

Desta forma, a SAN aparece em diferentes e complementares níveis: é uma necessidade humana básica (implicação biológica), sendo, portanto um direito humano fundamental; "se relaciona com a autonomia com que um país ou um povo se insere no sistema agroalimentar mundial"; e “está vinculada à qualidade alimentar e às formas de apropriação do território para a produção, processamento, circulação e consumo alimentar" ${ }^{\prime 10}$.

Tratando-se de SAN, constata-se que o padrão de consumo alimentar tem sofrido sérias modificações ao longo das últimas três décadas. Observou-se um aumento no consumo de açúcar e gorduras e níveis insuficientes de consumo de hortaliças e frutas. Nota-se ainda que alimentos tradicionais na dieta do/a brasileiro/a, como o arroz e o feijão, perderam a importância, enquanto o consumo de produtos industrializados, como biscoitos e refrigerantes, aumentou em $400 \%$.

Por outro lado, é importante considerar que a causa da insegurança alimentar e nutricional no Brasil não está na produção de alimentos, mas nas condições de acesso da população aos alimentos necessários para a dieta - "a forma como se produz, quem produz, onde se produz e para quem se produz colocam em cheque o modelo de desenvolvimento do ponto de vista da segurança alimentar"9.

Soma-se a isto o modelo de agricultura vigente, que é excludente e baseado em um conjunto de tecnologias da Revolução Verde, ou seja, baseado no desenvolvimento de novas variedades de sementes e plantas híbridas e transgênicas, no uso de agrotóxicos e fertilizantes sintéticos, na utilização de grandes infraestruturas de irrigação, cultivo intensivo do solo, monoculturas, etc. Esse modelo tem mudado, portanto, ao longo dos tempos, a forma de cultivo, os produtos cultivados e os hábitos alimentares das pessoas no campo e nas cidades.

A Revolução Verde, apesar de pregar o aumento da produção e produtividade, "não contribuiu para a redução da fome epidêmica e endêmica no país ${ }^{4}$ e no mundo, favoreceu o êxodo rural

4 Nota do original ${ }^{11}$ : "Resgatando aqui as ideias de Josué de Castro, em Geografia da Fome, que muito discutiu que a fome não pode mais ser atribuída a fenômenos naturais e, sim, aos sistemas econômicos e sociais que não benefiISSN 1982-8829

Tempus, actas de saúde colet, Brasília, 8(2), 157-171, jun, 2014// 
e a degradação ambiental, entre outros fatores extremamente negativos", colocando, então, em questionamento a eficácia econômica, social e ambiental deste modelo de agricultura industrial ${ }^{11}$.

No MST, assim como em outros movimentos sociais, o conceito de Segurança Alimentar e Nutricional articula-se ao conceito de Soberania Alimentar que, por sua vez, corresponde ao "direito que os povos, países, ou união de Estados têm para definir suas políticas agrícolas e alimentares e proteger sua produção e sua cultura alimentar"12. A Soberania Alimentar parte do pressuposto de que:

O direito individual à alimentação se articula a uma dimensão social de como este é produzido, considerando práticas que respeitam o meio ambiente, relações igualitárias entre as pessoas, o acesso aos recursos naturais envolvidos nesta produção, como a água, a terra, as sementes e os mercados locais ${ }^{12}$.

Assim, o conceito de Soberania Alimentar supera o conceito de Segurança Alimentar e Nutricional à medida que traz a reflexão sobre o direito humano à alimentação, sem desconectar da dimensão política, econômica e social desse fenômeno ${ }^{5}$.

Diante desse contexto, a Agroecologia surge como a matriz produtiva e social possível e ocupa papel de destaque. Entendemos aqui Agroecologia como "a aplicação de conceitos e princípios ecológicos no desenho e manejo de agroecossistemas sustentáveis", ou seja, uma nova abordagem da agricultura e do desenvolvimento agrícola que alie os recursos da agricultura tradicional local com os conhecimentos e métodos ecológicos modernos ${ }^{13}$.

De acordo com Ungarelli1 ${ }^{14}$, a Agroecologia é um campo de conhecimento científico que se alinha à proposta da Ecologia de Saberes, uma vez que também visa alterar determinadas práticas sociais.

Para o Conselho de Segurança Alimentar e Nutricional Sustentável (CONSEA), a Agroecologia deve ser implantada enquanto política estratégica de promoção da segurança alimentar da população brasileira, como forma de acesso a uma alimentação adequada e saudável. A Declaração da IV Conferência Nacional de Segurança Alimentar e Nutricional realizada em 2011 apresenta como proposição a necessidade de:

ciam a maior parte da população brasileira. Para ele, exemplo de fome epidêmica é a que ocorre no sertão nordestino, caracterizado pelas secas periódicas e que quando ocorrem levam seus habitantes ao limite da inanição. Mais do que o clima, o maior problema é a falta de recursos, de meios de transporte e de políticas públicas. Já na fome endêmica, que acomete grande parte do território brasileiro, a população sofre de uma fome permanente, sofrendo carências na alimentação cotidiana. Esta fome se manifesta ocultada por outras doenças que se instalam facilmente em organismos enfraquecidos. Se a falta total de alimentos constitui uma causa importante da mortalidade, o número é diminuto comparado às debilidades que o regime alimentar defeituoso provoca".

5 Neste trabalho, não optamos por usar o termo que articula estas duas dimensões - Soberania e Segurança Alimentar e Nutricional - SSAN - pois durante o desenvolvimento das atividades com os/as trabalhadores/as rurais foi utilizado o termo Segurança Alimentar e Nutricional - SAN. Ao utilizarmos o termo SAN neste artigo não o desconectamos das implicações políticas, econômicas e sociais propostas pela Soberania Alimentar. 
Fomentar processos de transição agroecológica e estimular as redes de promoção agroecológica, bem como apoiar iniciativas tais como: a conservação de sementes crioulas e tradicionais e dos parentes silvestres e plantas cultivadas; a constituição de sistemas locais públicos de abastecimento e comercialização; a economia solidária e mercado justo, na perspectiva da segurança alimentar e nutricional ${ }^{15}$.

Particularmente em áreas de Reforma Agrária e nas comunidades tradicionais que possuem algum tipo de organização coletiva e política, a Agroecologia "é a possibilidade de produzir de forma mais sustentável, de manter as famílias que desejam viver da terra no campo e de produzir alimentos de qualidade acessíveis a qualquer pessoa" ${ }^{11}$.

No âmbito do MST, a Agroecologia é tomada como uma matriz tecnológica viável para a produção agropecuária dos camponeses e camponesas Sem Terra, como meio de garantir o sustento e a renda, bem como forma de resistência ao modelo vigente e permanência na terra ${ }^{16}$.

De acordo com Gaia ${ }^{11}$ :

[...] existem centenas de iniciativas de Agroecologia sendo desenvolvidas nos acampamentos e assentamentos do MST neste Brasil a fora. Entre tantas práticas agroecológicas podemos citar: resgate de sementes e variedades crioulas, uso de caldas, biofertilizantes, compostagem e cobertura morta, reflorestamento, curvas de nível, diversificação da produção, adubação verde, cultivo em aléias, sistemas agroflorestais, plantio mínimo, uso da homeopatia e da fitoterapia, etc. Além das técnicas, existe, enquanto prática agroecológica no MST, o empoderamento político dos agricultores e agricultoras, técnicos(as) e dirigentes $[\ldots]^{11}$.

Desta forma, em assentamentos e acampamentos de Reforma Agrária, a discussão da SAN assume diversos aspectos, desde o aprimoramento da alimentação em si, quanto às condições de produção agropecuária e saúde da família e a possibilidade de geração de trabalho e renda - ou seja, é uma temática que favorece a melhoria da condição de vida de uma forma ampla. Do quintal e da roça, a produção vai direto para a mesa da família. Então, a forma de produzir torna-se fator diretamente relacionado à manutenção da saúde e segurança alimentar e nutricional das famílias.

Esse é um aspecto que integra o conceito de Saúde do MST:

Entendemos que para ter saúde é preciso que as condições de vida sejam garantidas: terra e trabalho; condições de moradia; educação de qualidade; alimentação saudável, sem venenos e conservantes; meio ambiente limpo e conservado; lazer e bem-estar, etc $^{17}$.

Além disso, podemos constatar esse aspecto como um dos objetivos estratégicos para a Saúde no MST, o qual propõe "lutar contra o modelo de saúde capitalista expresso no complexo ISSN 1982-8829 Tempus, actas de saúde colet, Brasília, 8(2), 157-171, jun, 2014// 
$164 / /$

médico-industrial-farmacêutico e no agronegócio, e ressignificar a saúde na perspectiva da classe trabalhadora, garantindo a saúde como dever do Estado ${ }^{18 \%}$.

Por fim, é importante considerar o papel de destaque ocupado pela matriz tecnológica de produção para a mudança da situação de saúde das populações do campo, da floresta e das águas, assim como reconhecido no documento da Política Nacional de Saúde Integral das Populações do Campo e da Floresta (PNSIPCF).

\section{A experiência e seus aprendizados}

A experiência analisada foi desenvolvida em três áreas de Reforma Agrária organizadas pelo MST-MG: Assentamento Comunidade de Resistência, no município de Funilândia; Assentamento Dois de Julho, em Betim; e Assentamento Ho Chi Minh, no município de Nova União. A experiência envolveu diretamente cerca de quatro militantes de cada área e indiretamente as demais famílias assentadas/acampadas. As/os participantes eram, na sua maioria, mulheres, adultas, com diversos níveis de inserção na organização das suas áreas. Essas, além de serem a maioria dos integrantes, foram também as que mais se envolveram no processo, dando-nos dicas da relação do tema SAN com a questão de gênero.

O Assentamento Ho Chi Minh conta com 42 famílias e foi oficialmente criado em 2005. O Assentamento Comunidade de Resistência foi criado em 2004 e possui 20 famílias. Já o Assentamento Dois de Julho possui 64 famílias e foi oficialmente criado em $2010^{6}$. Ressalta-se que as famílias já residiam nessas áreas muitos anos antes da criação oficial dos assentamentos pelo Instituto Nacional de Colonização e Reforma Agrária (Incra).

Os/as trabalhadores/as pertencentes às áreas de acampamento e assentamento coordenadas pelo MST-MG organizam-se em grupos de famílias, denominados de Núcleos de Base, e em Setores como Saúde, Educação, Produção, Formação, Comunicação, Frente de Massa, Direitos Humanos, Juventude e Cultura, para a realização de tarefas e discussões específicas. Cada grupo de famílias ou Setor tem seus representantes que, juntos, formam a coordenação do acampamento/assentamento. Foi por meio desta organização interna que se buscou dialogar com as comunidades envolvidas, desde a escolha dos/as participantes da experiência aqui relatada, ao fortalecimento do Setor de Saúde local e à tomada de decisões sobre a saúde da comunidade.

O Projeto “Atenção à Saúde do Campo: contribuições da Educação Popular" envolveu a realização de seminários, encontros, visitas aos acampamentos/assentamentos e reuniões. Estiveram presentes o conhecimento da realidade (diagnóstico da situação de saúde e produção agropecuária),

6 Na ocasião da experiência relatada, o Assentamento Ho Chi Minh aguardava a divisão dos lotes, o Assentamento Resistência estava em fase de construção das moradias definitivas e o Dois de Julho era acampamento. Por se tratar de uma área antiga, alguns aspectos da comunidade do Dois de Julho assemelhavam-se às demais áreas de assentamento, como a organização das famílias e a quantidade e diversidade da produção de alimentos. 
a socialização de saberes, oficinas, apresentação de experiências e visitas e o planejamento das ações em saúde a ser desenvolvidas nas respectivas comunidades.

Alguns dos recursos pedagógicos utilizados referem-se a materiais como boletins, cartilhas e vídeos, rodas de conversas, oficinas, intercâmbio e socialização de experiências - todos envolvendo os temas centrais SAN, Agroecologia, Saúde, etc.

Como ponto de partida da prática pedagógica, desenvolveu-se a construção coletiva do "Conceito de Saúde do MST". Nesta construção as/os trabalhadoras/es afirmaram que: "Saúde para nós é trabalhar em conjunto com os outros Setores, tendo organicidade , hábitos saudáveis, boa convivência entre os membros da comunidade, cooperação no trabalho, cultura, lazer, tranquilidade, segurança, trabalho, preservação do meio ambiente e moradia”.

Este conceito serviu de base para a construção do roteiro de diagnóstico da situação de saúde e produção agropecuária e, posteriormente, para a definição dos eixos de formação e intervenção na realidade. A realização do diagnóstico em cada área teve como objetivos: 1) conhecer as condições de vida da comunidade e sua relação com os problemas de saúde; 2) conhecer as potencialidades e os recursos locais que poderiam ser mais bem utilizados para a promoção da saúde; 3 ) conhecer o imaginário em saúde das famílias e identificar suas capacidades organizativas e interesses em torno da saúde local.

O roteiro do diagnóstico era composto de memória ${ }^{8}$ do Setor de Saúde, observação e registro fotográfico da área e do entorno, entrevista com representantes dos Setores de Educação e Produção, entrevistas com os/as assentados/as e acampados/as e visita ao serviço público de saúde responsável pelo atendimento à comunidade. No campo da segurança alimentar, tais perguntas relacionaramse à situação da alimentação, da produção de alimentos, das condições ambientais nas áreas e dos potenciais para o desenvolvimento de estratégias educativas nesta temática.

O levantamento das condições ambientais (por meio da observação e do registro fotográfico) contribuiu, principalmente, para tornar conhecida a utilização de agroquímicos pelas famílias e produtores vizinhos. Na entrevista com os/as integrantes do Setor de Educação, foi possível conhecer um pouco mais sobre a situação de segurança alimentar e nutricional das crianças, bem como visualizar as necessidades no âmbito da Educação em Saúde. Nas entrevistas com os/as assentados/ as e acampados/as, pode-se perceber como enxergam a relação entre produção, alimentação e saúde, emergindo, então, algumas necessidades educativas nestas áreas. $\mathrm{Na}$ entrevista com membros do Setor de Produção, as questões apresentaram-se sob o ponto de vista da produção saudável, do acesso aos meios de produção e aos recursos naturais, das condições ambientais, do acesso aos alimentos e de uma alimentação saudável.

7 Refere-se ao devido funcionamento da estrutura orgânica (instâncias) da área ou do MST como um todo. 8 O memorial consistiu em um roteiro no qual o coletivo debatia e registrava a sua trajetória, as ações coletivas desenvolvidas, os saberes em saúde produzidos nesse processo e como observavam essa trajetória. 
Assim, no que tange à segurança alimentar e produção agropecuária, de modo geral, o diagnóstico mostrou-nos que a produção agropecuária não garantia todas as necessidades alimentares de grande parte das famílias e alguns produtos precisavam ser adquiridos no mercado. A maioria das famílias usava insumos químicos na produção, (principalmente adubos químicos e agrotóxicos) e grande parte destas não percebia a relação entre a utilização dos agroquímicos e a saúde, sobretudo dos agrotóxicos. Existiam algumas experiências isoladas (individuais ou em pequenos grupos) em andamento, visando à transição para uma produção agroecológica. Em todas as áreas existia boa disponibilidade de água para a produção. A água não era melhor aproveitada por carência de estrutura de transporte e armazenamento no local da produção. Os riscos de contaminação da produção pelo entorno eram grandes, sendo causados, principalmente, pelo uso de agrotóxicos por produtores vizinhos, ou pelos rios que banham as áreas e carregam esgotos industriais.

Embora as/os envolvidas/os na realização do diagnóstico já conhecessem a realidade (uma vez que são moradoras/os dos referidos espaços), o que se pretendeu ao realizá-lo foi reconhecer informações subjetivas, veladas ou tão óbvias que pareciam inexistentes por serem naturalizadas. Com isso, o diagnóstico possibilitou o autoconhecimento do grupo na realidade objetiva em que se encontrava, as ações que realizavam, o nível de consciência e as interpretações que se tem sobre esta realidade ${ }^{19}$. Por este motivo, Oliveira e Oliveira $^{20}$, afirmam que o estudo da realidade vivida e a percepção dos sujeitos constituem-se como ponto de partida e matéria prima do processo educativo.

Em seguida, a construção dos eixos de intervenção ${ }^{9}$ integrou o processo de planejamento, que tentou dar unidade às informações do diagnóstico (tanto dentro de cada acampamento/assentamento, quanto entre eles), estabelecendo uma visão mais integradora do conjunto da realidade e apontando as possibilidades/necessidades de ação.

Para cada área foram escolhidos três eixos de intervenção e propostas algumas estratégias de ação. No Assentamento Dois de Julho, propôs-se a construção de um horto medicinal, o fortalecimento de atividades de lazer, esporte e cultura e ações de Educação Ambiental. No Assentamento Resistência, propôs-se o desenvolvimento de oficinas de plantas medicinais, a organização do grupo produtivo de mulheres e ações de Educação Ambiental em parceria com a Educação de Jovens e Adultos (EJA) e com as crianças. No Assentamento Ho Chi Minh, propôs-se, por meio de um projeto vigente $^{10}$, desenvolver ações educativas sobre alimentação saudável, produção agroecológica, cultivo e utilização de plantas medicinais e Educação Ambiental.

A socialização de saberes e a vivência com as práticas de saúde foram desenvolvidas ao longo da experiência, com o objetivo de problematizar a realidade e visualizar estratégias de saúde a ser desenvolvidas nas comunidades. As temáticas de formação acompanharam os eixos de intervenção definidos no projeto.

9 Os eixos de intervenção construídos no projeto foram: Alimentação saudável; Práticas de cuidado em Saúde; Saneamento e higiene; Produção saudável; e Convivência, lazer e cultura.

10 Projeto Agricultura Urbana e Periurbana, que contou com o financiamento do Ministério de Desenvolvimento Social e Combate à Fome (MDS). 
Contando com a colaboração de educadores/as populares do Grupo SEMEAR ${ }^{11}$ foram desenvolvidas oficinas de segurança alimentar e visita para conhecer a experiência do grupo. Nessas oficinas desenvolveu-se a relação entre alimentação e saúde, o valor nutricional dos alimentos, e a valorização dos saberes tradicionais na alimentação. Como oficina prática, trabalhou-se o aproveitamento integral de alimentos e de ervas nativas. Nesse momento foi possível estabelecer conexões entre saúde, alimentação e plantas medicinais.

Ao final da experiência, uma oficina de Saneamento Ecológico e Permacultura permitiu a construção de um olhar para o espaço da casa sobre a ótica da produção de alimentos, articulado às demandas de saneamento, conforme os princípios da Agroecologia e da Permacultura. Nesse momento, foi possível estabelecer conexões entre o saneamento ecológico e a segurança alimentar.

Por fim, é importante destacar a contribuição de filmes documentários como "O arredor de casa $^{21}$ ", "Resistir e Saber Cuidar 22 " e "Agrotóxicos: Envenenando a Vida ${ }^{23}$ ", que propiciaram às/aos trabalhadoras/es o contato com outras experiências de saúde, o acesso a importantes informações relacionadas ao tema, além de serem geradores de debates entre as/os participantes.

Dessa forma, a partir de nossa observação, acompanhamentos posteriores aos Assentamentos e relatos dos/as integrantes do Setor de Saúde de cada área, pudemos presenciar algumas mudanças em torno das práticas de segurança alimentar das/os trabalhadoras/os rurais envolvidos. As receitas culinárias e medicinais aprendidas foram rapidamente socializadas com outras mulheres das áreas, que passaram a incorporar novos hábitos na produção de alimentos. A socialização e a valorização de hábitos alimentares saudáveis ocorreram de forma a valorizar alguns dos recursos agrícolas geralmente não aproveitados. Cita-se aqui o consumo de plantas nativas (como o caruru-bredo), de partes de plantas não aproveitadas (como a folha da cenoura e da beterraba) e a utilização das ervas medicinais na alimentação.

Essas mudanças nos hábitos alimentares puderam ser observadas principalmente nas pessoas que participaram diretamente das atividades desenvolvidas, ou nas pessoas mais próximas, vizinhas ou que participavam do mesmo grupo de famílias na área. Gadelha e Weitzman9 contribuem para a compreensão desse processo, uma vez que, segundo eles, os hábitos alimentares são construídos na trama das relações sociais, principalmente nas relações de amizade e vizinhança. Por outro lado, mostrou a demanda de uma prática educativa que envolvesse o conjunto das famílias assentadas/acampadas. Além disso, foi possível a visibilidade e a valorização do trabalho produtivo desenvolvido pelas mulheres no entorno das casas.

Nessa perspectiva, um fator que pode ter contribuído no planejamento de ações de segurança alimentar refere-se à antecedência de algumas experiências de transição para a Agroecologia nas áreas de Reforma Agrária. No Assentamento Ho Chi Minh, a existência de experiências de

11 O SEMEAR é um grupo de trabalho comunitário do Bairro Alto Vera Cruz, em Belo Horizonte, que tem como foco o resgate das práticas populares em saúde, entre elas a segurança alimentar e nutricional e as plantas medicinais, e contou durante alguns anos com a assessoria da Rede de Intercâmbios e Tecnologias Alternativas. 
transição agroecológica certamente contribuiu para a escolha da alimentação saudável como um eixo do planejamento.

Assim, o debate em torno da alimentação saudável apresentou-se em estreita relação com o tema da produção saudável e trouxe à tona a necessidade de ações relacionadas à transição de matriz de produção para a Agroecologia. Tais questões nos chamam a atenção para as especificidades do tema da SAN no contexto da Reforma Agrária, com destaque para a formação em Agroecologia.

Embora muito presente nos discursos de diversos/as trabalhadores/as rurais, a Agroecologia mostrou-se um termo "distante" de algumas pessoas. Em uma discussão sobre o tema, a maioria afirmou desconhecer o significado deste conceito, apesar de, depois de informadas, identificarem em suas práticas alguns dos seus princípios.

Considerando-se que o eixo Plantas medicinais apresentou-se como uma estratégia comum ao planejamento de saúde em todas as áreas, percebe-se aqui um grande potencial de mobilização para a promoção da SAN, sobretudo entre as mulheres. Esta relação mostrou-se fortalecida pelo uso de temperos e alimentos como remédios naturais, pelo uso das ervas medicinais na alimentação, ou pelo incentivo à produção consorciada de plantas medicinais e horticultura, principalmente nos quintais.

Por fim, é importante destacar que, nessas áreas, as mulheres passaram a se auto-organizar em grupos para o desenvolvimento de atividades relacionadas à formação política e econômica, produção agropecuária, economia solidária, plantas medicinais e garantia de direitos. Em alguma medida, a auto-organização das mulheres possibilitou a continuidade do trabalho de Educação Popular no âmbito da Saúde e da Segurança Alimentar, bem como o desenvolvimento de ações pactuadas nesta experiência.

\section{CONSIDERAÇÕES FINAIS}

Analisar uma prática educativa sob a ótica da SAN mostra-nos que as diversas dimensões que compõem uma concepção ampliada de saúde não se separam no âmbito do território. Embora as análises apresentadas neste artigo nos remetam aos eixos de produção e alimentação saudável, ao se discutir SAN, os temas saneamento, higiene, cultura, plantas medicinais, entre outros, mostraramse interligados.

No âmbito da Reforma Agrária, discutir segurança alimentar implica em discutir produção agropecuária, já que esta é a base da produção da existência dos/as trabalhadores/as rurais, além de se constituir como uma das dimensões fundamentais da SAN. A formação em segurança alimentar requer, portanto, ações que envolvam a mudança de matriz tecnológica de produção e que não fiquem restritas ao Setor de Saúde, mas abranjam o conjunto das instâncias do MST. Com isso, a prática educativa em segurança alimentar apresenta-se como uma possibilidade de início de 
modificação desta realidade. Por outro lado, este trabalho não deve ocorrer descolado de um recorte de gênero, já que, uma vez mais, as mulheres se mostraram guardiãs da biodiversidade e dos hábitos alimentares saudáveis.

Assim, os aprendizados aqui relatados mostram a necessidade de se fortalecer e integrar os distintos saberes na busca da SAN dos sujeitos da Reforma Agrária, na construção epistemológica da Ecologia de Saberes. Trata-se, assim, de uma experiência marcada pelo diálogo de saberes, nos quais os saberes formalizados e os saberes científicos não se sobressaem ou, mesmo, são negligenciados, mas articulados aos saberes de experiência dos trabalhadores e trabalhadoras da Reforma Agrária. Conforme o próprio Boaventura de Sousa Santos nos ensina, a utopia do interconhecimento consiste em aprender outros conhecimentos, sem esquecer os nossos próprios; ampliando-se assim a intervenção no mundo real.

\section{REFERÊNCIAS}

1. Caldart RS. Educação do Campo: Notas para uma Análise de Percurso. Trab. Educ. Saúde (Rio de Janeiro). 2009; 7(1); 35-64.

2. Freire P. Pedagogia do Oprimido. 17ª ed. Rio de Janeiro: Ed. Paz e Terra; 1987.

3. Paludo C. Educação Popular. In: Streck, DR, Redin E, Zitkoski JJ. Dicionário Paulo Freire. $2^{\text {a }}$ ed., ver. ampl. Belo Horizonte: Autêntica Editora.

4. Santos BS. A Gramática do Tempo: para uma nova cultura política. São Paulo: Cortez; 2006.

5. Santos B. Para além do pensamento abissal. Novos Estudos. 2007:71-94

6. Weitzman R. Educação Popular em Segurança Alimentar e Nutricional: uma Metodologia de Formação com Enfoque de Gênero. Belo Horizonte: Rede de Intercâmbio de Tecnologias Alternativas. Belo Horizonte: 2008. p.168-191.

7. Bringel B. Scott VR. Pesquisa Militante e Produção de Conhecimentos: o enquadramento de uma perspectiva. Rio de Janeiro: 2014. Disponível em http://netsal.iesp.uerj.br/images/diversos/ Texto-base.pdf

8. Conselho de Segurança Alimentar de Nutricional. Declaração da II Conferência Nacional de Segurança Alimentar e Nutricional. Recife; 2004.

9. Gadelha E, Weitzman R. A Segurança Alimentar e Nutricional no Contexto dos Movimentos Sociais. In: Weitzman R. Educação Popular em Segurança Alimentar e Nutricional: uma Metodologia de Formação com Enfoque de Gênero. Belo Horizonte: Rede de Intercâmbio de 
10. Silva CEM. Sustentabilidade e Segurança alimentar. In: Cáritas Brasileira Regional Minas Gerais/Instituto de Terras do Estado de Minas Gerais. Programa de Segurança Alimentar e Nutricional em Assentamentos do Estado de Minas Gerais - 2000/2003.

11. Gaia MCM. Agroecologia: a resistência do camponês e da camponesa Sem Terra. Rio Pomba. Monografia [Especialização em Agroecologia e Desenvolvimento Sustentável] - Centro Federal de Educação Tecnológica de Rio Pomba 2008

12. Sempreviva Organização Feminista. Soberania Alimentar: uma resposta às mudanças climáticas. 2009.

13. Gliessman S. Agroecologia: processos ecológicos em agricultura sustentável. $3^{\text {a }}$ ed. Porto Alegre: Editora da UFRGS; 2005.

14. Ungarelli DB. A Comunidade Quilombola Kalunga do Engenho II: Cultura, produção de alimentos e ecologia de saberes. Brasília. Dissertação [Mestrado em Desenvolvimento Sustentável] - Centro de Desenvolvimento Sustentável. UnB; 2009.

15. Conselho de Segurança Alimentar de Nutricional. Declaração da IV Conferência Nacional de Segurança Alimentar e Nutricional. Salvador; 2011.

16. Movimento dos Trabalhadores Rurais Sem Terra, AS-PTA - Agricultura Familiar e Agroecologia, Instituto Giramundo Mutuando. Agroecologia: notas introdutórias e análise de agroecossistemas. Apostila do curso de Agroecologia e Biossegurança. Mimeo: 2005

17. Movimento dos Trabalhadores Rurais Sem Terra. Coletivo Nacional de Saúde. Lutar por saúde é lutar por vida. Caderno de Saúde n.1: 1999.

18. Movimento dos Trabalhadores Rurais Sem Terra. Coletivo Nacional de Saúde. Boletim Informativo: 2007.

19. Hurtado CN, organizador. Educar para Transformar, Transformar para Educar: Comunicação e Educação Popular. Petrópolis: Vozes; 1993. Tradução de R. Dias.

20. Oliveira RD, Oliveira MD. Pesquisa Social e Ação Educativa: Conhecer a Realidade para Poder Transformá-la. In: Brandão CR. Pesquisa Participante. $7^{\mathrm{a}}$ ed. São Paulo: Ed. Brasiliense; 1988. p 17-33.

21. O arredor de casa [DVD]. Dirigido por Nilton Pereira. Borborema. Assessoria e Serviços a Projetos em Agricultura Alternativa. Polo Sindical e das Organizações da Agricultura Familiar de 
Borborema; s/d. (25:32 min.), son, color.

22. Resistir e Saber Cuidar [DVD]. Dirigido por Cecília Figueiredo. Brasília: Triângulo Produções, 2006. (35 min.), son, color.

23. Agrotóxicos - Envenenando a Vida [DVD]. Dirigido por Sergio Brito. Rio de Janeiro: Escola Nacional de Saúde Pública, 2000. (30 min), son, color.

Artigo apresentado em 07/04/14

Artigo aprovado em 20/05/14

Artigo publicado no sistema em 29/06/14 